\title{
KATA-KATA SERAPAN DALAM ALQURAN PERSPEKTIF ULAMA TAFSIR
}

\author{
Fajriyani Arsya \\ LAIN Bukittinggi, yaniiainbukittinggi86@gmail.com
}

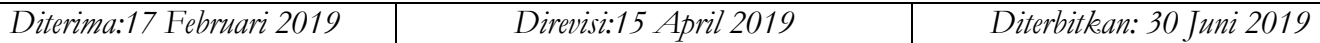

\begin{abstract}
One of the issues debated by Arab linguists and interpreters of the Quran is whether all the words in the Koran come from native Arabic, or are there uptake words from foreign languages used in the Koran. The analysis of linguists states that the absorption words in various languages can arise due to geographical location, trade relations, immigration, politics, culture, economy, industry, and others. In the context of absorption words in the Koran the scholars are divided into three opinions, namely the group of scholars who reject the absorption of words in the Koran; Second, groups who believe that there are absorption words in the Koran; and third, which takes a middle ground with a view that the word uptake in the Koran has its specificities.
\end{abstract}

Keywords: Uptake Words, Dynamics of the Quran Language, Ulama of Tafsir.

\begin{abstract}
Abstrak
Salah satu permasalahan yang menjadi kajian para pakar bahasa Arab dan pakar tafsir Alquran adalah apakah semua kata dalam Alquran itu turunan dari bahasa Arab asli, atau terdapat kata serapan dari bahasa asing yang dipakai dalam Alquran. Analisis para abli bahasa menyebutkan bahwa kata serapan dalam berbagai bahasa dapat muncul disebabkan oleh faktor kondisi geografis, relasi perdagangan, jalur imigrasi, politik, konstruksi budaya, ekonomi, industri dan sebagainya. Dalam konteks kata serapan dalam Alquran para ulama terbagi pada tiga pendapat, yaitu kelompok ulama yang menolak adanya kata serapan dalam Alquran; Kedua, kelompok yang berpendapat adanya kata serapan dalam Alquran; dan ketiga yang mengambil jalan tengah dengan suatu pandangan bahwa kata serapan dalam Alquran memiliki kekehususan tersendiri.
\end{abstract}

Kata Kunci: Kata Serapan, Dinamika Bahasa Alquran, Ulama Tafsir.

\section{PENDAHULUAN}

Perkembangan sejarah kebudayaan umat manusia terbentuk dalam kurun waktu yang relatif panjang dimana terjalin suatu proses bargaining antar budaya dan bahasa. Hal ini meniscayakan suatu kenyataan bahwa bahasa manusia memikili keterkaitan dan saling mempengaruhi antara satu bahasa dengan bahasa lainnya. Tak satu pun bangsa di dunia ini yang lantang mengakui bahwa bahasa yang dimilikinya terbebas dari unsur-unsur penga-ruh bahasa dari bangsa-bangsa lainnya. Tak terkecuali bahasa Arab yang disinyalir mendapat pengaruh dan masukan dari peradaban bangsa lainnya. Hal ini terjadi disebabkan bangsa Arab sebelum Islam telah mengalami dialog interaktif dengan komunitaskomunitas yang berada bangsa Arab, semisal bangsa Aram, ${ }^{1}$ Persia, Romawi, Suryani, ${ }^{2}$ dan

1Penyebutan "Aram" dalam literatur modern dikaitkan dengan pelafalan bahasa orang-orang Armenia, Azerbaijan, Israel, Georgia, Lebanon, Suriah dan Turki. Secara geografis, bahasa Aram dipergunakan di kawasan Timur Tengah dan Asia Tengah, mulai dari wilayah pantai Levant di Laut Mideterania hingga menyebar ke Timur wilayah sungai Tigris. Lalu orang-orang Yahudi menyebarkan bahasa Aram ke wilayah Afrika Utara dan wilayah Eropa. Sejarah bahasa Aram itu sendiri diperkirankan berlangsung selama 3000 tahun. Lihat, Klaus Beyer, The Aramic Language, Gottingen: Vandehoek and Ruprech, 1986, 38-43 
bangsa lainnya. Salah satu model relasi politik dan bisnis (tijarah) antara bangsa Arab dengan bangsabangsa lainnya adalah relasi antara bangsa Arab dengan bangsa Aram dan bangsa-bangsa lainnya dalam berbagai persoalan kehidupan. Kenyataan ini memberikan illustrasi mengenai kondisi saling mempengaruhi antar bangsa-bangsa yang saling berinteraksi tersebut, termasuk keterpengaruhan dalam perso-alan kebahasaan. ${ }^{3}$

Dalam kaitan ini terdapat pertanyaan sederhana yang bergulir di kalangan para pakar kebahasaan, yakni apakah kitabAlquranmenggunakan atau mendapat pengaruh dari unsur-unsur bahasa asing atau tidak? Kajian seperti ini tidak banyak dilakukan oleh para pakar ilmu-ilmu Quran selain imam As-Suyûthi. ${ }^{4}$ Tidak banyak ulama yangmengintrodusirkajian bahasa serapan dalam pem-bahasan ilmu-ilmu Alquran, lain halnya dengan kaum orientalis ${ }^{5}$ yang getol mempropagandakan kajian ini sebagai pintu masuk menggugat keaslian kitab suci Alquran.

Dalam ilmu kebahasaan telah muncul istilah penyerapan bahasa Asing ke dalam bahasa Arab yang disebut dengan ta'rib (peng-Araban). Lalu istilah bagi kata serapan hasil dari "peng-Araban" dinamakan dengan al-mu'arrab(sesuatu yang diArabkan). Imam Al-Jawaliqîmengintrodusir istilah al-Mu'arrab sebagai kata-kataasing yang muncul di dalam Alquran, Hadis Nabi, Atsar para sahabat, puisi-puisi atau syair, dan juga teks-teks

2Istilah bangsa Suryani atau bahasa Suryani menurut para ahli sejarah dikaitkan dengan nabi Nuh as dan keturuannnya. Lihat, Ibnu Katsir, Al-Bidayah wa al-Nihayah, tt. tp.

${ }^{3}$ Ramadhan Abdul At Tawwab, Fushul fi Fiqhi Al Arabiyah, Kairo: Maktabah Al Khonji, 1999 Cet. II, 38

${ }^{4}$ Lihat, Abdurrahman Jalaluddin al-Suyuthi, Al-Itqan fi Ulum al-Quran, Beirut: Dar al-Fikr, tt. 10

${ }^{5} \mathrm{Di}$ antara tokoh orentalis yang getol mengkaji katakata serapan dalam al-Quran, yaitu Abraham Geiger, Theodore Noeldeke, Arthur Jeffery, Ignaz Goldziher dan lain-lain. klasik. ${ }^{6}$ Tentu saja, kajian tentang kata serapan dalam Alquran -yang bagi kalangan tertentu dipandang rumit atau menyisakan kekhawatiran tentang munculnya keraguan tentang orisinalitas bahasa Alquran sebagai kitab suci yang diturunkan dengan bahasa Arab sebagaimana disebut dalam ayat "Sesunggubnya Kami menurunkannya berupa Alquran dengan berbahasa Arab, agar kamu memahaminya” (QS. Yûsuf: 2).

Di luar kekhawatiran tentang orisinal bahasa Alquran sesungguhnya hal ini tidak menjadi beban dalam interaksi kebahasaan, sebab hal itu merupakan perkara yag lumrah. Artinya, kitab suci Alquran dapat dinyatakan sebagai berbahasa Arab, walaupun di dalamnya terdapat kata-kata atau istilah --yang menurut para pakar bahasa sebagai berasal dari bahasa di luar Arab. Masalahnya, orang-orang Arab saat di mana Alquran diturunkan memang sudah menganggapnya bagian dari bahasa Arab, walaupun para pakar sejarah bahasa akan menganggapnya bahwa kata-kataatau istilah itu berasal dari bahasa lain.

Sebagai contoh kata "qirthâs" (kertas) yang disebut dalam Alquran diklaim oleh para pakar bahasa sebagai bagian dari pengaruh bahasa lain. Lalu permasalahnnya, apakah masyarakat Arab pada saat Alquran diturunkan tidak mengetahui maknanya? Analisa lain bahwa bangsa Arab saat itu sudah tahu arti dari kata "qirthâs" yang disebut dalam QS Al-An'am ayat 7, sehingga Alquran pun mempergunakan istilah itu, walau dituduh sebagai masukan dari bahasa lain. Perdebatan berikutnya, apakah sekiranya dikatakan Alquran berbahasa Arab, lalu diharamkan kitab suci ini dari unsurunsurbahasa serapan yang sudah menjadi fenomena pada setiap bahasa? Tulisan ini akan melihat tentang pandangan para ulama tafsir tentang katakata serapan dalam kitab suci Alquran?”

'Lihat, Karim Sayyid Ghonim. Al Lughoh Al Arabiyah wal As Shofwah Al Ilmiyah Al Haditsah, (Kairo: Maktabah Al Khonji, 1999), 109 


\section{DINAMIKA BAHASA SERAPAN DALAM BERBAGAI BAHASA}

Dinamika Kebahasaan

Dalam percakapan sehari-hari sering diungkapkan kata-kata yang secara kebahasaan mirip dengan sebuah bahasa dari bahasa yang lain. Dalam bahasa Indonesia misalnya, kata "rakyat" artinya, komunitas masyarakat suatu bangsa diduga dekat dengan bahasa Arab dari kata "raiyah" (komunitas yang dipimpin), sehingga muncul dugaan bahwa kata "rakyat" berasal dari bahasa Arab. Kata "sahabat karib" diduga dari bahasa Arab, yaitu dari kara "al-shahabah" dan "al-qarib", artinya teman dan dekat, maka sahabat karib dimaknai sahabat dekat. Kemudian kata-kata yang muncul dalam Panca Sila disinyalir muncul katakata serapan dari bahasa Arab, seperti kata 'adil (dari kata al-'adl), beradab (al-adab), kerakyatan (raiyah), hikmah (bikmah), permusyawaratan (almusyawarab), perwakilan (al-wakalah), dan keadilan (al-'adalab).

Demikian juga dengan kata-kata akses dari kata (acces), aksesori (accessory), akomodasi (accomodation), akun (account), akting (acting), aktivis (activis, aktor (actor), aktris (actres), pulpen (ballpoint), balon (ballon), buku (book), bus (bus), kalender (calender), kampus (campus), kartun (cartoon), karir (career), karismatik (charismatuic), kopi, (coffee), kolusi (collution), data (data), dekade (decade), departemen (department), deteksi (detection), deterjen (detergent), diagnosa (diagnose) diktator (dictator), dilema (dilemma), dimensi (dimention), disertasi (disertation) dan seterusnya.

Contoh-contoh kata serapan di atas menunjukkan bahwa terdapat ragam kata dan istilah dalam suatu bahasa yang diduga kuat berasal dari bahasa lain. Fakta tentang munculnya bahasa asing dalam suatu bahasa menjelaskan bahwa bahasa tersebut memiliki interaksi dengan bangsa lain yang memiliki bahasa berbeda. Pola interaksi kebangsaan inilah yang kemudian melahirkan dinamika kebahasaan.
Faktor Munculnya Bahasa Serapan

Terdapat beberapa faktor yang menyebabkan terjadinya pola suatu bahasa yang mengambil dari bahasa lain. Sebagai contoh, pada bahasa Indonesia, munculnya bahasa serapan yang masuk ke dalam bahasa ini selain disebabkan faktor interaksi masyarakat, juga disebabkan faktor pesatnya ilmu pengetahuan di berbagai bidang dan kehidupan. Dalam kaitan ini kemajuan dalam berbagai bidang pengetahuan,keilmuan, seni dan teknologi dapat memperluas kosakata dalam bahasa-bahasa di dunia, termasuk dalam bahasa Arab, dan bahkan bahasa Alquran itu sendiri.

Secara garis besar sumber perluasan kosakata terbagi dua, yaitu sumber internal dan sumber eksternal. Pertama, Sumber internal. Yaitu, swadaya bahasa dalam bahasa internalnya. Artinya, pengayaan bahasa yang dapat terwujud melalui beberapa pola, di antaranya: (i) aktivasi kata-kata lama; (ii) pembentukan kata-kata baru; (iii) penciptaan kata-kata baru; dan (iv) pengakroniman. Sebagai contoh pengaktifan kata-kata lama dalam bahasa Indonesia dapat dilihat dari munculnya beberapa kata, seperti kata "baheula" (bahasa Sunda) yang berarti zaman dulu, atau munculnya kata-kata baru seperti "zaman now" untuk menyebut zaman sekarang.

Kedua, Sumber luar dapat terjadi melalui perluasan dari bahasa-bahasa serumpun, dan sebagainya. Perluasan bahasa dari bahasa lain atau bahasa serumpun biasa terjadi lantaran adanya interaksi sosial dan intensitas komunikasi. Sebagai contoh perluasan bahasa Indonesia sebagai diduga berasal dari bahasa Arab. Para ahli bahasa memperkirakan kosa kata bahasa Indonesia atau bahasa Melayu yang diduga serapan dari bahasa Arab relatif sangat banyak, diperkirakan sebanyak 2000 3000 kata, atau diperkirakan 10\% sampai 15\% dari bahasa Indonesia/ Melayu keseluruhanya. Perluasan-perluasan bahasa Indonesia dari bahasa Arab, misalnya, dapat ditemui dalam kata-kata sebagai berikut: abad, abadi, adat, adil, amal, alamat, akal, 
akhir, almanak, asal, adzan, bakhil, baligh, barokah, hikmah, hikayat, halal, haram, ilmu, insan, jawab, khas, khianat, khidmat, khitan, kitab, kursi, kertas, lapaz, munafik, muallaf, musyawarah, markas, mistar, malaikat, mahkamah, musibah, maut, mimbar, nisbah, syariat, syahwat, ulama, wajib, ziarah dan sebagainya.

\section{Pola Perluasan Kebahasaan}

Sebagaimana disebutkan sebelumnya bahwa pola perluasan kebahasaan dapat dilihat dari dua pola, yaitu pola perluasan internal dan eksternal. Pola perluasan eksternal atau berasal dari sumber luar menjadi contoh kajian menarik dalam penelitian ini. Sebagai contoh, dalam bahasa Indonesia pola perluasan ekternal, atau perluasan bahasa Indonesia dari bahasa Arab dapat dilihat dari beberapa pola berikut.

1. Pelafalan dan makna bahasa masih sesuai dengan aslinya. Kata-kata berikut merupakan perluasan dari bahasa Arab dimana lafal dan artinya masih sama dengan aslinya, seperti katakata "abad, abadi, adat, adil, amal, alamat, almanak, awal, akbir, adzan, bakhil, baligh, barokah, hikmah, bikayat, halal, baram, haji, ilmu, insan, jawab, khas, khianat, khidmat, khitan, kitab, kursi, kertas, lapar, munafik, muallaf, musyawarah, markas, mistar, mailaikat, mabkamah, musibah, maut, mimbar, nisbah, napas, syariat, syahwat, ulama, wajib, ziarah, dan sebagainya.

2. Pelafalannya telah berubah meski artinya tetap sama. Berikut contoh-contoh kata dalam bahasa yang populer di tanah air yang berasal dari bahasa Arab yang lafalnya berubah, tetapi artinya masih sama. Yaitu, kata "berkah, barakat, atau berkat dari kata barakah, kabar dari khabar, katulistiwa dari khatulistiwa, lafal dari lafazh, lalim dari zhalim, rezeki dari rizq, serikat dari

${ }^{7}$ Lihat Kamus Bahasa Indonesia terbitan Balai Pustaka. Lihat juga, Pierre Labrouse, Kamus Umum IndonesiaPerancis, Paris: Association Archipel dan Jakarta: Gramedia, 1985. syirkah, atau semisal nama hari Ahad (dari kata Ahadun) Senin dari Itsnain (artinya dua), Selasa dariTsulasa (tiga), Rabu dari Arbi'a (artinya empat), Kamis dari kata Khamis (artinya kelima), Jumat dari Jumu'ah, dan Sabtu dari istilah Sabtun.

3. Pelafalan dan maknaya telah berubah dari sebelumnya. Pola ini dapat dilihat dari beberapa contoh kata, seperti kata "keparat" (dalam bahasa Indonesia dimakna dengan cacian atau makian, berasal dari "kufarat" yang artinya kafir); kata logat (yang berati dialek, berasal dari bahasa Arab dari "lughah" yang berarti bahasa); kata perlu (berasal dari kata bahasa Arab "fardhu"); kata laskar (dari kata bahasa Arab "askar" artinya serdadu atau prajurit).

4. Lafalnya benar, tetapi artinya berubah. Pola ini dapat dijumpai dalam beberapa kata seperti kata "ahli" (orang yang mempunyai kemampuan/pakar). Kata "ahli” berasal dari bahasa Arab, yaitu Ahli, artinya komunitas yang berasal dari suatu daerah. Kemudian kata "kalimat" (artinya rangkaian kata-kata), berasal dari bahasa Arab yang berarti kalimat, dan sebagainya. ${ }^{8}$

\section{BAHASA SERAPAN DALAM BAHASA ALQURAN}

Dinamika Bahasa Dalam Bahasa Arab

Sudah merupakan perkara lumrah bahwa bahasa di berbagai belahan dunia mendapat masukan bahasa lain, seperti yang terjadi dalam bahasa di tanah air. Pengaruh dan mempengaruhi biasanya muncul sebagai akibat dari suatu pola hubungan interaktif dan hubungan sosial. Dalam bahasa Ibu Pertiwi, misalnya, pengaruh datang dari bangsa-bangsa yang pernah menjajah negeri ini, seperti Belanda, Inggris, Portugis dan Jepang. Selain pengaruh dari para penjajah, juga muncul dari bangsa-bangsa yang pernah melakukan kontak

${ }^{8}$ Lihat, Russel Jones, Arabic Loan-Words In Indonesian, A Check-List of Words of Arabic and Persian Origin in Bahasa Indonesia and Traditional Malay, In The Reformed Spelling, London: School of Oriental and African Studies, 1978 
bisnis dengan masyarakat di tanah air, seperti orang-orang Arab, Cina, Persia, dan India. Tak terkecuali, bahasa Sansekerta yang diduga kuat telah mempengaruhi bahasa di tanah air lantaran bahasa ini dijadikan sebagai bahasa sastra dan perantara dalam penyebaran agama Hindu dan Buddha. Ragam pengaruh tadi membentuk kata-kata serapan dalam bahasa Indonesia yang dipakai hingga saat ini.

Dalam konteks bahasa Arab, pengaruh tersebut terutama datang dari bangsa yang pernah mengunjungi negeri ini, seperti Persia. Pengaruh juga datang dari bangsa yang berada disekitar negeri Arab. Sejak sebelum Alquran diturunkan, bahasa Arab disinyalir telah dipengaruhi oleh bahasabahasa yang berasal dari bahasa lain. Sebagai contoh munculnya kata serapan dari bahasa Ibrani dan Suryani. Contoh kongkrit, yaitu kata kata "Ibrabim" dan "Ismail" yang berasal dari bahasa Ibrani. Perkembangan bahasa Arab yang cukup signifikan terjadi pada saat dunia Islam dikuasai oleh kekhalifahan Turki Utsmanidimana pada saat itu bahasa Arab diperkaya oleh bahasa-bahasa yang dominan di dunia, seperti bahasa bahasa Latin, bahasa Italia, Turki, Spanyol hingga bahasa Perancis. ${ }^{10}$ Bahkan, sebuah penelitian yang dilakukan oleh Syamsul Hadi menyebutkan bahwa bahasa Arab telah mengalami perluasan dari bahasa Inggris yang diperkirakan lebih dari 3000 kata. ${ }^{11}$

Dari penelitian Syamsul Hadi dapat diketahui bahwa bahasa Arab, sebagaimana bahasa lain di dunia, telah mengalami proses perluasan dari bahasa aslinya. Kata-kata "al-Majistir" dalam bahasa Arab berasal dari kata Latin "Magister", kata-kata "Yanayir" dari kata Yunani Januarius, "Fabrayir" dari kata Februarius, "Maris" dari kata Mars, kata "Abril"

\footnotetext{
${ }^{9}$ Muhammad Sirchan, Fqih al-Lughah, Riyadh: Maktabah Riyadh, 1956, 72

${ }^{10}$ Abdul Rahman, Ad-Dakhil Fi al-Lughah al-Arabiyah wa Labjatiha, Madinah: tp., 1975, 4

${ }^{11}$ Syamsul Hadi, Kata dan Istilah Asing Dalam Bahasa Arab, Jurnal Humaniora, Vol. 1, tahun 1995, 113-120
}

dari kata Aprilis. Kata-kata bahasa Arab "alDemoqratiyah" berasal dari Yunani "democratia", kata bahasa Arab "Aristokratiyab" dari kata Aristocratia. Kemudian kata dalam bahasa Arab "al-Thamatim" artinya tomat berasal dari kata bahasa Spanyol, yaitu "tomate", kata "riyal" (mata uang SaudiaArabia) dari kata Spanyol "real". Kemudian kata dalam bahasa Arab "ubera" dari bahasa Italia "opera", kata "istudiya" dari kata Italia "studio", kata bahasa Arab "jiyulujia" dari bahasa Italia "geologia", dan sebagainya. ${ }^{12}$

Beberapa contoh di atas memberikan penjelasan bahwa secara umum bahasa di berbagai belahan dunia mengalami perluasan atau pengayaan yang disebabkan oleh faktor interaksional di antara masyarakat di sekitarnya. Tak terkecuali bahasa Arab yang nota bene merupakan bahasa yang dekat dengan bahasa kitab suci Alquran. Dari fakta kebahasaan inilah selanjutanya dapat dipahami tentang kemungkinan bahasa Alquran yang mengalami penyerapan dari bahasa-bahasa lain di luar bahasa Arab itu sendiri.

Selanjutnya, kata asing yang diserap kedalam bahasa Arab, terbagi kepada tiga pola perluasan, sebagai berikut:

1. Kata asing yang pelafalan dan penulisannya disesuaikan dengan aturan bahasa Arab, seperti درهم (dirham).

2. Kata asing yang dirubah tetapi tidak disesuaikan dengan aturan-aturan bahasa Arab.

3. Kata yang tidak semuanya diserap kedalam bahasa Arabdimanakata ini tidak disesuaikan dengan aturan bahasa Arab. Pengucapannya punmasih mengikuti bahasa asalnya seperti خرسان (khurasan) ( )

Beberapa contoh di atas menjelaskan tentang pola-pola perluasan bahasa Arab sebagai-mana perluasan dalam bahasa-bahasa lainnya. Pola ini sekaligus menunjukkan bahwa bahasa Arab telah Arab..., 114 ${ }^{12}$ Syamsul Hadi, Kata dan Istilah Asing Dalam Bahasa 
mengalami suatu prose pengayaan atau perluasan, sehingga bahasa Arab merupakan salah satu bahasa yang ada di dunia yang dinamis, tidak statis, dan berkembang mengikuti perkembangan zaman.

\section{Bahasa Serapan Dalam Bahasa Alquran}

Keberaadaan bahasa serapan dalam kitab suci Alquran memang masih menyisakan polemik. Meski bahasa serapan itu ada dalam Alquran, akan tetapi banyak ulama yang menganggapnya sebagai bukan bahasa serapan melainkan bagian dari kekhususan atau keistimewaan bahasa Alquran itu sendiri. Salah seorang ulama yang berpendapat seperti ini adalah Imam Al-Thabari, pengarang kitab tafsir yang sangat terkenal di era klasik.

Tetapi demikian terdapat pandangan ulama yang meratifikasi adanya bahasa serapan dalam Alquran. Pendapat yang disebut belakangan ini membutuhkan penguatan-penguatan argumen tentang pola perluasan bahasa Alquran dari bahasa asing atau bahasa serapan. Berikut ini beberapa pola perluasan bahasa Alquran yang meliputi ta'rib (arabisasi), isytiqaq (pengambilan) dan an-Nakht (penyingkatan).

\section{Ta'rib (Pola Arabisasi)}

Alquran sebagai pedoman hidup umat Islam diturunkan dalam bahasa Arab. Bahasa Arab yang terdapat didalamnya tentu juga mengandung kosa kata yang berasal dari bahasa Arab dan bahasa asing. Inilah yang disebut oleh orang Arab dengan at-Ta'rib. Akan tetapi para ulama berbeda pendapat tentang ada atau tidaknya at-Ta'rib dalam Alquran. Sebagian dari mereka ada yang menolak seperti Abu Ubaidah dan ada pula yang berpendapat bahwa kata serapan ada di dalam Alquran.

كرب Secara etimologi kata "ta'rib” berasal dari memiliki arti “mewarnai suatu kalimat dengan lafal asing dalam bahasa Arab”. Definisinya yaitu lafal-lafal yang dipergunakan masyarakat Arab, yang diambil dari bahasa asing. Dari definisi ini al-
Ta'rib merupakan kosa kata yang diserap oleh masyarakat Arab dari bahasa asing yang kemudian dipergunakan oleh mereka.Yakni, kata asing yangdiambil kedalam bahasa Arab, dalam prosesnya boleh jadi mengalami semacam pengu-rangan, penambahan ataupun penukaran sehingga bahasabahasa tersebut menjadi bahasa Arab asli.

Manurut Syahin, istiqaq dimaksudkan dengan membuat bentuk kata dari kata yang laindan terjadi perubahan pada bentuk dan makna. Dari kata "dharaba" (telah memukul) bisa dibentuk kata "dhâribun" (pemukul) atau "yang dipukul" (madhrûb). Bentuk isytiqaq banyak dijumpai dalam Alquran. Sedangkan istilah Nakht (dari kata nahatayanhitu, artinya memahat) dijumpai dalam ayat aquran "Watunbitûna min al-jibâli buyûtan âminîn: Dan kamu pahat sebagian dari gunung-gunung untuk dijadikan rumah-rumah dengan rajin". Istilah ini berarti formulasi dua kata atau lebih menjadi satu ungkapan baru yang menunjukkan makna aslinya. Dalam penggunaannya, nakht dijumpai dalam berbagai bahasa, termasuk dalam bahasa Arab.

\section{Kekhususan Bahasa Alquran}

Salah seorang pakar Tafsir, Imam Al-Thabari, telah merilis tentang kata-kata serapan dari bahasa asing ini di muqaddimahtafsirnya. Hal itu dirilis dalam satu bab khusus dengan tajuk "al-Qoulfi-lbayan anal-abruf allaty ittafaqat fiba alfatal-Araby wa alfar. ghairaha min ba'diajnamal-umam". Kemudian dipertegas melalui penjelasannya pada bagian sub bab tafsirnya. Menurut al-Thabari, terdapat ragam argumen bahwa Alquran itu berbahasa Arab (dan bukan bahasa asing) disebabkan kitab suci Alquran itu diturunkan kepada Nabi Muhammad Saw. Yang nota bena diutus dari bangsa Arab, dan kaumnya sendiri merupakan masyarakat Arab. Hal ini sebagaimana dinyatakan dalam firman-Nya, "Sesunggubnya Kami menurunkannya berupa Alquran dengan berbahasa Arab agar kamu memahaminya" QS. Yûsuf, ayat 2. 
Dan firman Allah yang menegaskan bahwa Alquran diturunkan dengan menggunakan bahasa Arab merupakan decisionmutlak Tuhan, dan tidak boleh siapapunmengkhususkannya hanya pada beberapa ayat tanpa ayat yang lainnya. Ini mirip seperti perkataan para ulama yang menyebutkan "bahwa sebagian isi Alquran adalah bahasa Ethopia bukan Arab, sebagian Persia bukan Arab...." dan tidak boleh juga mengatakan bahwa Alquranmenggunakan bahasa Ethiopic, Persia, Turki ataupun bahasa asing lainnya."

Dalam konteks ini pendapat at-Thabari bahwa dalam Alquran terdapat kata-kata yang dipakai oleh orang Arab seperti kata "al-Qirthas", "al-Misykat", "al-Istabraq", "al-Tabhîl”, "al-ShabunalTannûr". Kata-kata ini juga dipakai oleh bangsa Persia, Turki atau Ethopia dengan kesepakatan dalam pemakaian bahasa antar bangsa-bangsa dengan hanya terdapat satu arti. Maka, setiap kata yang muncul dalam Alquran tidak bisa diklaim sebagai sebagai bahasa non-Arab, melainkan sebagai salah satu bahasa yang juga dipakai oleh bangsa lain (selain Arab) dengan pemaknaan yang mungkin sama ataupun berbeda.

\section{Pengambilan Bentuk Kata Dalam Struktur Bahasa Arab}

Terdapat karakteristik bahasa Arab yang berbeda dengan karakteristik bahasa lainnya. Karakteristik ini menjadikan bahasa Arab sebagai bahasa yang fleksibel, dinamis, dan mempunyai tingkat elastisitas tinggi. Dalam menjalankan fungsinya sebagai bahasa komunikasi, sarana dalam penyampaian tujuan agama, pencatatan berbagai ilmu pengetahuan, maka bahasa ini mampu menyampaikannya dengan sangat mudah dan benar.

Beberapa keunggulan bahasa Arab terkait ini, yaitu Pertama, Isytiqaq. Yang dimaksud dengan isytiqaq adalah pengambilan sighat (bentuk kata) dari sighat yang lain, karena ada persamaan bentuk, maknadan strukturnya dengan beberapatambahan yang telah ditetapkan. Menurut ulama Basrah, sumber isytiqaq (pengambilan) adalah bentuk masdar, sedangkan menurut pakar bahasa Kufah sumber isytiqaq dalah kata kerja (fi il). Isytiqaq menurut para pakar ilmu bahasa terbagi tiga macam, yaitu:

(a) Isytiqaq shagir yang aplikasinya melalui tasrif yang dikenal dengan pengembangan lafadz dari lafadz asli dengan syarat terdapat kesesuaian dari segi makna, huruf dan urutan.Sebagai contoh: dharaba - dhâribun - madhrûb.

(b) Isytiqaq kabir disebut juga al-qalbal-luqhawi, yaitu adanya persamaan antara dua kata dari segi lafadzdan makna, hanya saja urutan hurufnya tidak sama. Contohnya kata "hamida" dan "madaha"; dan

(c) Isytiqaq Akbar disebut juga al-ibdalal-liqhawi, yaitu menukar suatu huruf yang lain. dalam proses ini huruf yang mengalami pertukaran tidak disyaratkan memiliki makhraj yang sama. Boleh saja terjadi pada setiap huruf karena yang penting disini adanya kesesuaian makna antara dua lafadz, sebagai contoh kata: yang memiliki makna suatu dengan dua lafadz yang berbeda.

Kedua, An-Nabt. An-Naht adalah membuat kata baru yang ambil dari dua unsur kata yang berbeda atau lebih tetapi tetap menunjukan pada makna yang diambil baik berupa isim dan fi iil. Perkembangannya harus sesuai dengan kaidah (wazan) bahasa Arab yang terdapat dalam tashrif, sebagai contoh "basmalah" untuk kalimat "Bismillabirrabmanirrabim" dan "hamdalah" untuk kalimat "alhamdulillahirabbil 'alamin", dan seterusnya.

\section{PENDAPAT PARA ULAMA TENTANG KATA SERAPAN DALAM ALQURAN}

Terdapat seratus lebih kata serapan dalam Alquran yang tersebar dalam berbagai surat. Katakata serapan tersebut hampir familiar dalam telinga umat Islam, yang sebagian dari mereka akan menganggap sebagai bahasa asli bahasa Arab. Dalam kaitan ini para ulama telah merilis kata-kata 
serapan dalam berbagai kitab mereka. Syaikh Imam Al-Jawaliqi, Ibnu Jarir dan Jalaluddin as-Suyuti, misalnya telah meyebutkan beberapa contoh katakata serapan dalam Alquran sesuai urutan abjad.Berikut ini akan disebutkan beberapa kata serapan dalam Alquran yang dilansir oleh para ulama dengan estimasi asal pengambilan kata tersebut, artinya serta letaknya dalam Alquran.

\begin{tabular}{|c|c|c|c|}
\hline $\begin{array}{c}\text { Kata } \\
\text { Searapan }\end{array}$ & $\begin{array}{c}\text { Asal } \\
\text { Bahasa }\end{array}$ & Arti & $\begin{array}{c}\text { Letak Surat } \\
\text { dan Ayat }\end{array}$ \\
\hline أباريق & Persia & Jalan air & $\begin{array}{l}\text { Al-Waqiah: } \\
18\end{array}$ \\
\hline أب & $\begin{array}{l}\text { Penduduk } \\
\text { Barat }\end{array}$ & Rumput & 'Abasa: 13 \\
\hline إبلعى & Habasyah & Telanlah & Hud : 44 \\
\hline أخلد & Ibrani & $\begin{array}{l}\text { Cendeung } \\
\text { kepada dunia }\end{array}$ & $\begin{array}{l}\text { Al-A'raf } \\
176\end{array}$ \\
\hline ألأر ائك & Habsyah & Kasur-kasur & Al-Kahfi: 31 \\
\hline آزر & Persia & Bapak & $\begin{array}{l}\text { Al-An'am : } \\
37\end{array}$ \\
\hline أسباط & & Kelompok & $\begin{array}{l}\text { Al-A'raf : } \\
159\end{array}$ \\
\hline أسفار & Suryaniyah & Buku & $\begin{array}{l}\text { Al-Muddasir } \\
: 34\end{array}$ \\
\hline إصرى & Nabathea & Janji Setia & Ali Imran: 81 \\
\hline أليم & Ibrani & Menyakitkan & $\begin{array}{l}\text { Al-Baqarah : } \\
10\end{array}$ \\
\hline أليم & Ibrani & $\begin{array}{l}\text { Orang yang } \\
\text { yakin }\end{array}$ & Hud: 75 \\
\hline الممللة الآخرة & Qibthi & $\begin{array}{l}\text { Yang } \\
\text { pertama }\end{array}$ & Shad: 7 \\
\hline بعير & Ibrani & $\begin{array}{l}\text { Seberat } \\
\text { beban seekor } \\
\text { unta }\end{array}$ & Yusuf : 65 \\
\hline تتور & Persia & $\begin{array}{l}\text { dapur tempat } \\
\text { memasak } \\
\text { Roti }\end{array}$ & Hud : 4 \\
\hline ربيع & Persia & & $\begin{array}{l}\text { Al-Baqarah : } \\
254\end{array}$ \\
\hline تتبير ا & Nabathea & $\begin{array}{l}\text { Membinasak } \\
\text { an }\end{array}$ & Al-Isra: 5 \\
\hline الجبت & Habasyah & Nama Syetan & An-Nisa: 50 \\
\hline
\end{tabular}

\begin{tabular}{|l|l|l|l|}
\hline & Ibrani & $\begin{array}{l}\text { Nama } \\
\text { Neraka }\end{array}$ & $\begin{array}{l}\text { Al-Baqarah : } \\
207\end{array}$ \\
\hline حهن & Zinjiyah & Bahan Bakar & $\begin{array}{l}\text { Al-Anbiya : } \\
97\end{array}$ \\
\hline حواريون & Nabathea & Sahabat Setia & Ali Imran: 52 \\
\hline دراست & Yahudi & $\begin{array}{l}\text { Kamu saling } \\
\text { membaca }\end{array}$ & $\begin{array}{l}\text { Al-An'am } \\
150\end{array}$ \\
\hline ربيون & Suryaniyah & $\begin{array}{l}\text { Orang } \\
\text { Banyak }\end{array}$ & $\begin{array}{l}\text { Ali Imran : } \\
146\end{array}$ \\
\hline الرحمن & Ibrani & Pengasih & $\begin{array}{l}\text { Ar-Rahman : } \\
1\end{array}$ \\
\hline الرقيم & & Sumur & Qaf : 12 \\
\hline & Romawi & Tinta & Al-Kahfi : \\
\hline
\end{tabular}

Terdapat tiga kelompok ulama yang berpendapat mengenai eksistensi kata serapan dalam kitab suci Alquran. Ketiga kelompok itu adalah kelompok ulama yang menolak adanya kata serapan dalam Alquran; kelompok ulama yang berpendapat adanya kata serapan dalam Alquran; dan kelompok yang mengambil jalan tengah.

Di antara para ulama yang berpendapat mengenai tidak adanya kata serapan adalah Imam as-Syafii, Ibnu Jarîr, Abu 'Ubaidah, dan Qadhî Abu Bakar. Menurut mereka di dalam alquran tidak dijumpai kata serapan. Para pakar dari kelompok ini berdalih dengan ayat-ayat berikut:

(Pertama), Surat Yusuf ayat 2,"Sesunggubnya Kami menurunkannya berupa Alquran berbabasa Arab, agar kamu mengerti". Tentang ayat ini para ulama memberikan komentar, di antaranya Imam AlThabari yang berpendapat bahwa AllahSwt menurunkan Alquran kepada nabi Muhammad Saw dalam bahasa Arab lantaran bahasa mereka adalah bahasa Arab. Kemudian Ibnu Katsîr berpendapat bahwa Alquran diturunkan dengan bahasa Arab supaya mereka mengetahui makna dan memahami kandungannya. Lalu, menurut Imam as-Samarkandi bahwa Allah menurunkan malaikat Jibril as supaya ia membacakan Alquran kepada nabi Muhammad dalam bahasa Arab. Firman Allah "Dan sekiranya Alquran kami jadikan sebagai bacaan dalam bahasa selain 
bahasa Arab niscaya mereka mengatakan, mengapa tidak dijelaskan ayat ayat-nya? Apakah patut (Alquran) dalam bahasa selain bahasa arab sedang rasul, orang arab?” (QS: Fussilat: 44).

Penafsiran yang dikemukakan oleh para ahli tafsir seperti Ibnu Abbas, Mujahid, Ikrimah dan Said bin Jubair terhadap ayat ini adalah bahwaSeandainyaAlquran itu seluruhnya diturunkan dalam bahasa asing, niscaya berkata pula orang Quraisy dengan inkar, "Kenapa tidak dijelaskan ayatnya dalam bahasa asing dan bahasa Arab?, mereka juga berkata "bagaimana mungkin ayat Alquran turun dalam bahasa asing sedangkan Rasul yang menerimanya adalah bangsa Arab?"

Kedua, Ulama yang menerima adanya kata Serapan dalam Alquran. Kelompok ini menjawab pendapat ulama yang mengatakan bahwa tidak ada kata serapan dalam Alquran dengan alasan "bahwa kalimat-kalimat dari bahasa Arab yang bersentuhan dengan kalimat-kalimat non-Arab, tidak menjadikannya keluar dari bahasa Arab, seperti syair berbahasa Persia yang tidak keluar dari kaidah sastra Persia hanya karena adanya satu kata yang diambil dari bahasa Arab. Ulama yang termasuk dalam kelompok ini adalah Ibnu Abbas, an-Naqib dan al-Juwaini, mereka berpendapat bahwa kata serapan ada didalamAlquran". Dalil firman Allah Swt: "Dan kami tidak mengutus seorang rasulpun, melainkan dengan bahasa Kaum-nya" (QS: Ibrahim:4).

Terkait dengan ayat ini Imam az-Zamakhsari berpendapat bahwa Rasulullah Saw tidaklah diutus kepada bangsa Arab saja akan tetapi untuk semua ummat manusia secara umum dimana bahasa mereka juga bermacam macam. Dalil firman Allah, "Katakanlah (Mubammad), wabai manusia! sesunggubnya aku ini utusan Allab bagi kamu semua" (QS: al-A'raf: 158). Imam Al-Razi menyebutkan bahwa kata قوم bukanlah penduduk negeri (bangsa Arab saja) akan tetapi penduduk negeri secara umum dalil (QS: alA'raf: 158), bahkan kepada golongan jin dan manusia. Dalilnya yaitu firman Allah dalam surat al-
Isra, "Katakanlah sesunggubnya jika manusia dan Jin berkumpul untuk membuat yang serupa (dengan) Alquran ini mereka tidak akan dapat membuat yang serupa dengannya, sekalipun mereka saling membantu satu sama lain.'(QS: al-Isra': 88). Kemudian Imam Al-Thabari mengatakan bahwa diutusnya Rasul sebelum nabi Muhammad kepada suatu umat dengan bahasa yang dipakai dan dipahami oleh suatu kaum tersebut, supaya mereka mengerti dan mempercayai ajarannya.

Ketiga, Ulama yangmengkombinasikan dua pendapat di atas. Ulama yang termasuk dalam kelompok ini adalah al-Jawaliqi, Ibnu Jauji dan Jalaluddin as-Suyuti, "Mereka berpendapat bahwa kata-kata serapan itu pada dasarnya adalah kata-kata asing seperti yang dikatakan ahli fiqh, tetapi kata kata itu meresap ke dalam bahasa Arab. Maka bangsa Arab membentuknya sesuai dengan lisan mereka dan mengubahnya dari bahasa asing menjadi bahasa Arab. Kemudian turunlah Alquran sedangkan kosa kata kosa kata itu telah bercampur dengan bahasa Arab. Maka siapa yang berkata bahwa itu adalah bahasa Arab maka itu telah benar, dan siapa yang berkata bahwa itu adalah bahasa asing maka itu adalah benar".

Setelah pembahasan tiga pendapat yang dimunculkan oleh ketiga kelompok ulama di atas dan bila dicermati lebih dalam lagi, maka tiap-tiap pendapat dari kelompok tersebut ada benarnya sesuai dengan dalil dan argumen yang dikembangkan oleh masing-masing kelompok. Kelompok yang menolak mengatakan bahwa tidak ada kata serapan dalam Alquran dengan dalil dari ayat-ayat Alquran dan kata serapan itu memang bukanlah bahasa Arab asli, kata serapan itu berasal dari bahasa Asing, maka benar jika dikatakan tidak ada kata serapan dalam Alquran. Hal ini dapat dilihat dari contoh kosa kata serapan dalam Alquran. Kata serapan itu berasal dari bahasa Asing seperti bahasa Persia, Ibrani, Habsyah, India, Qibthi, Suryani, Nabathea, Barber, Romawi. 
Kelompok yang menerima mengatakan bahwa ada kata serapan dalam Alquran dengan argumen dan dalil yang mendukung pendapat mereka. Menurut mereka kata serapan itu ada dalam Alquran karena Alquran itu ditujukan kepada semua umat manusia bahkan kepada bangsa Jin dengan demikian maka haruslah di dalamnya ada suatu isyarat kepada berbagai macam bahasa untuk menyempurnakan pencakupan terhadap umat manusia.

\section{PENUTUP}

Kesimpulan dari penelitian ini adalah pandangan para ulama tentang kata-kata serapan dalam Alquran yang terbagi pada tiga kelompok: Pertama, kelompok ulama yang menolak adanya kata serapan dalam Alquran; Kedua, kelompok ulama yang berpendapat adanya kata serapan dalam Alquran; dan kelompok ketiga yang mengambil jalan tengah dengan suatu pandangan bahwa kata serapan dalam Alquran memiliki kekhususan ter-sendiri.

\section{DAFTAR KEPUSTAKAAN}

Abdul Rahman, Ad-Dakbil Fial-Lughahal-Arabiyah wa Labjatiha, Madinah: tp., 1975

Al-Razi, Mafatihal-Ghaib, 2000, (http://www. altafsir.com), diakses 17 April 2011

Al-Suyuti, Jalaluddin, al-Mushir fi ulumal-Lugah wa an-Wau'ba, Kairo: dar at-Turas,tt, Jilid 1

Al-Suyuti, Jalaluddin, al-Itqan fi ulumAlquran, Libanon: Dar al-Kutub al-Ilmiyah,t, jilid 1

Anis, Ibrahim,dkk, al-Mu'jamal-Wassij, Kairo: Maktabah as-Suruk ad-Dauliyah, 2004, cet ke 4

Armas, Adnin, Kosa Kata Asing Alquran, artikel. http://harus masuk islam. wordpress.com/. Rabu, 23 Januari 2018

Brummer, Vincent, TheologyandPhilosophicallnquiry: An Introduction, New York: The MacmillanPress, Ltd. 1981

Departemen Agama RI,Alquran dan Terjemahannya, Jakarta: al-Huda, 2002
Ghonim, Karim Sayyid, Al Lughoh Al Arabiyahwal As Shofwah Al Ilmiyah Al Haditsah, (Kairo: Maktabah Al Khonji, 1999

Ibnu Katsir, Al-Bidayah waal-Nihayah,tt. tp.

Karim Sayyid Ghonim. Al Lughoh Al Arabiyahwal As Shofwah Al Ilmiyah Al Haditsah, (Kairo: Maktabah Al Khonji, 1999

Klaus Beyer, The Aramic Language, Gottingen: Vandehoekand Ruprech, 1986, h. 38-43

Ramadhan, Abdul At-Tawwab, Fushulfi Fiqhi Al Arabiyah, Kairo: Maktabah Al Khonji, 1999

Robinson, James M, "Hermeneutics Since Bith" dalam The New Hermeneutics, ed. J.M. Robinson dan John B. Cobb, New York: HapperandRow Publisher, 1964

Ramadhan Abdul At Tawwab, Fushulfi Fiqhi Al Arabiyah, Kairo: Maktabah Al Khonji, 1999 Cet. II

Richard E. Palmer, Hermeneutics: InterpretationTheory in Schleirmacher, Dilthey, Heideggerand Gadamer, Evanston: North Easteren Universitypress, 1969

Pierre Labrouse, Kamus Umum Indonesia-Perancis, Paris: AssociationArchipel dan Jakarta: Gramedia, 1985.

Russel Jones, ArabicLoan-Words In Indonesian, A Check-Listof Words of Arabic and Persian Origin in Bahasa Indonesia andTraditionalMalay, In The Reformed Spelling, London: Schoolof Oriental andAfricanStudies, 1978

Syahin, Muhammad Taifiq, 'Awamil al-Tanmiyah li al-Lughah al-Arabiyah, Kairo, Maktabah Wahbah, 1980

Sirhan, Muhammad, Fiqh al-Lughah, Riyadh: Maktabah Riyadh, 1956, h. 72

Syamsul Hadi, Kata dan Istilah Asing Dalam Bahasa Arab, Jurnal Humaniora, Vol. 1, tahun 1995

Samarkandi, Babrul Ulum, (www.qurancomplex. com), diakses 17 April 2011

Zamakhsari, Al-Kassaf, 2000, (http://www. altafsir.com), diakses 17 April 2017 